\title{
The effect of ductal diameter on surgical and medical closure of patent ductus arteriosus in preterm neonates: Size matters
}

Scott Tschuppert, ${ }^{\mathrm{a}}$ Carsten Doell, MD, ${ }^{\mathrm{b}}$ Romaine Arlettaz-Mieth, MD, ${ }^{\mathrm{c}}$ Oskar Baenziger, MD, ${ }^{\mathrm{b}}$ Valentin Rousson, PhD, ${ }^{\mathrm{d}}$ Christian Balmer, $\mathrm{MD}^{\mathrm{e}}$ René Prêtre, $\mathrm{MD}^{\mathrm{a}}$ and Ali Dodge-Khatami, $\mathrm{MD}, \mathrm{PhD}^{\mathrm{a}}$

From the Divisions of Congenital Cardiovascular Surgery, ${ }^{\mathrm{a}}$ Pediatric Intensive Care, ${ }^{\mathrm{b}}$ and Pediatric Cardiology, ${ }^{\mathrm{e}}$ University Children's Hospital; the Clinic of Neonatology, ${ }^{\mathrm{c}}$ University Hospital; and the Department of Biostatistics ${ }^{\mathrm{d}}$-University of Zurich, Zurich, Switzerland.

Received for publication May 24, 2007; revisions received June 14, 2007; accepted for publication July 9, 2007.

Address for reprints: Ali Dodge-Khatami, $\mathrm{MD}, \mathrm{PhD}$, Division of Congenital Cardiovascular Surgery, University Children's Hospital, University of Zurich, Steinwiesstrasse 75, 8032 Zurich, Switzerland (E-mail: ali.dodge-khatami@kispi.uzh.ch).

J Thorac Cardiovasc Surg 2008;135:78-82

$0022-5223 / \$ 34.00$

Copyright (๑) 2008 by The American Association for Thoracic Surgery

doi:10.1016/j.jtcvs.2007.07.027
Objective: We sought to analyze the effect of patent ductus arteriosus diameter on treatment success in premature neonates.

Methods: Among 537 consecutive neonates born between 1985 and 2005 with a diagnosed patent ductus arteriosus, 201 premature patients ( $<35$ weeks' gestation) treated for a hemodynamically significant patent ductus arteriosus were retrospectively reviewed. Two groups were compared: group MED ( $n=154$; successful treatment with indomethacin) and group FAIL ( $\mathrm{n}=47$; failure of medication to reduce the patent ductus arteriosus diameter to hemodynamic insignificance).

Results: After unsuccessful medical treatment, 33 patients required surgical patent ductus arteriosus closure, 12 died before further possible treatment, and 2 were discharged home without clinical symptoms but with an open patent ductus arteriosus. Mean patent ductus arteriosus diameter in the FAIL group $(2.8 \pm 0.9 \mathrm{~mm})$ was significantly larger than that in the MED group $(2.4 \pm 0.6 \mathrm{~mm}, P<.01)$. Assisted respiration time (ventilation plus continuous positive airway pressure) before patent ductus arteriosus closure was longer in the FAIL group (20 days) than in the MED group ( 9 days, $P<.001$ ) but was similar after patent ductus arteriosus closure. By using an index of patent ductus arteriosus diameter squared/birth weight (in square millimeters per kilogram), a cutoff value of less than $9 \mathrm{~mm}^{2} / \mathrm{kg}$ correctly predicts medical patent ductus arteriosus closure in $87.5 \%$ of patients. Values of greater than $9 \mathrm{~mm}^{2} / \mathrm{kg}$ correctly predict medication failure in $41.5 \%$ of patients.

Conclusions: In preterm babies requiring surgical patent ductus arteriosus closure, longer respiration times reflect a delay while attempting medical treatment, but respiration time is equally short between groups after shunt elimination. Medical treatment, although a valid first option, is likely to fail with larger patent ductus arteriosus diameters and lower birth weights. Unwarranted assisted respiration and corresponding hospital stay might be shortened by earlier surgical referral for patent ductus arteriosus closure in preterm babies with a patent ductus arteriosus index of greater than $9 \mathrm{~mm}^{2} / \mathrm{kg}$.

$\mathrm{P}$ rematurity increases the risk for patent ductus arteriosus (PDA) ${ }^{1,2}$ In extremely premature neonates (gestational age $<26$ weeks), the incidence of PDA has been reported to be as high as $30 \%$ to $67 \%$. $^{3,4}$ The left-to-right shunt caused by the PDA results in increased pulmonary blood flow and a steal from the systemic circulation. This might jointly be responsible for further comorbidities associated with PDA, ${ }^{5}$ such as chronic lung disease, ${ }^{6}$ intraventricular hemorrhage, ${ }^{4}$ necrotizing enterocolitis, ${ }^{7}$ or retinopathy. ${ }^{8}$ Early closure of the PDA has been shown to improve both cardiorespiratory status and long-term follow-up. ${ }^{9}$ Conservative treatment includes a stepwise initiation of fluid restriction, ${ }^{1}$ continuous positive airway pressure respiratory assistance, intubation, and mechanical ventilation with 


\section{Abbreviation and Acronym \\ $\mathrm{PDA}=$ patent ductus arteriosus}

decrease in inspiratory time and application of positive end-expiratory pressure, and cyclooxygenase inhibitors. ${ }^{3}$ Finally, when medical treatment fails, the PDA can be ligated surgically, ${ }^{8,10}$ but the optimal timing is still highly debatable. Outcomes, intensive care and hospital stay, costs involved, and sparse follow-up data raise the question of the optimal treatment algorithm for a hemodynamically significant PDA.

We reviewed our experience from the last 2 decades with this lesion and hypothesized that earlier surgical intervention to close the larger PDA would be safe and an alternative to predictable prior medical failure.

\section{Materials and Methods}

Permission to proceed with this study was granted by the Institutional Review Board of our Children's Hospital. Between January 1985 and December 2005, 537 consecutive premature neonates ( $<35$ weeks' gestation) with a diagnosed PDA were born in the Clinic of Neonatology of the University Hospital or referred to the Division of Neonatology at the University Children's Hospital. From this cohort, 201 babies were medically treated with prostaglandin synthetase inhibitors (indomethacin) for a hemodynamically significant PDA and constitute the study group. Nine neonates presented either with contraindications to medical treatment or with hemodynamic instability, so as to preclude an attempt at medical closure, and went directly to surgical PDA ligation; these are not included in this analysis. Two groups were defined: the MED group with 154 (77\%) babies treated successfully with indomethacin and the FAIL group with $47(23 \%)$ babies in whom medication failed to reduce the PDA diameter to hemodynamic insignificance. The FAIL group includes 33 patients who eventually required surgical ligation of the PDA, 12 neonates who died before surgical closure of the PDA, and 2 infants with a hemodynamically significant PDA but without clinical symptoms at the time of hospital discharge.

Hemodynamic significance was diagnosed either clinically or by means of echocardiographic analysis. Since 1996, echocardiography is routine in all premature babies in both study hospitals. Echocardiographic criteria for hemodynamic significance were dilatation of the left atrium (left atrium/aortic root ratio $>1.5$ ), as measured by means of M-mode scanning, and a pandiastolic retrograde flow from the ductus into the descending aorta. Measurements of the PDA considered the minimal diameter of the ductus in the black-and-white 2-dimensional cross-section image from a high-parasternal long-axis view. Before the echocardiographic era, clinical criteria included a systolic or continuous machinery murmur, bounding pulses, a clearly amplified precordium, and systemic hypotension.

The indication for medical treatment was weight dependent. For neonates weighing less then $1250 \mathrm{~g}$, echocardiographic diagnosis of a PDA was enough to start medical treatment, irrespective of hemodynamic significance. Babies weighing more than $1250 \mathrm{~g}$ needed to have either clinical symptoms or an echocardiographically proved significance of the PDA to indicate medical treatment. Treatment entailed $0.2 \mathrm{mg} / \mathrm{kg}$ intravenous indomethacin every 12 hours for 3 doses in the $1980 \mathrm{~s}$ or $0.1 \mathrm{mg} \cdot \mathrm{kg}^{-1} \cdot \mathrm{d}^{-1}$ for 6 days since then.

The criteria for surgical PDA ligation were failure of complete medical treatment or hemodynamic instability during ongoing but incomplete medical treatment. Surgical intervention was performed after achievement of general anesthesia and endotracheal intubation. The chest was entered through a muscle-sparing left posterolateral thoracotomy. The third intercostal space was entered, and the PDA was either ligated or clipped.

General patient demographics included gestational age, birth length and weight, sex, comorbidities (ie, chronic lung disease, intraventricular hemorrhage, necrotizing enterocolitis, and retinopathy), duration of intensive care unit stay, and length of hospitalization. Chronic lung disease was defined as oxygen dependence after 36 days of life with an initial gestational age of less than 32 weeks or oxygen dependence after 28 days of life with a gestational age of greater than 32 weeks. Data recorded before PDA closure included age and weight at closure, PDA diameter, left atrium/aortic root ratio, and the time of assisted respiration (continuous positive airway pressure time plus mechanical ventilation time) before closure. Data recorded after PDA closure included time of assisted respiration after closure, the echocardiographic confirmation of PDA closure, and postsurgical complications (chylothorax, recurrent laryngeal nerve damage, coarctation, iatrogenic ligation of the aorta, and pneumothorax).

Statistical analysis was performed by using logistic regression to compare the MED and FAIL groups with respect to continuous variables. This allowed us to use the same statistical method for both univariate analyses (testing for the significance of the relationship between 1 continuous variable, such as PDA diameter or birth weight, and the outcome) and multivariate analyses (testing for the joint influence of 2 variables, such as PDA diameter and birth weight, on the outcome). The Fisher exact test was used to compare both groups in terms of comorbidities. Continuous variables are presented as means and standard deviations.

\section{Results}

The PDA diameter was significantly smaller in the MED group $(2.4 \pm 0.6 \mathrm{~mm})$ than that in the FAIL group $(2.8 \pm$ $0.9 \mathrm{~mm}, P=.006)$. Birth weight was larger in the MED group $(1.1 \pm 0.3 \mathrm{~kg})$ than in the FAIL group $(1.1 \pm 0.3 \mathrm{~kg})$, without reaching statistical significance $(P=.22)$. In a multivariate analysis including both variables as predictors, the PDA diameter remained significant $(P=.002)$, and birth weight was almost significant $(P=.07)$. Looking for an index or ratio by using a measurable baseline patient characteristic that could help to predict outcome, we calculated the logistic regression of the logarithms of PDA diameter and birth weight. The regression coefficients were 2.209 and -1.111 , respectively. Because the amplitude of the former is about twice the amplitude of the latter, this suggested consideration of an index defined as "PDA diameter squared/birth weight" to predict the outcome. 


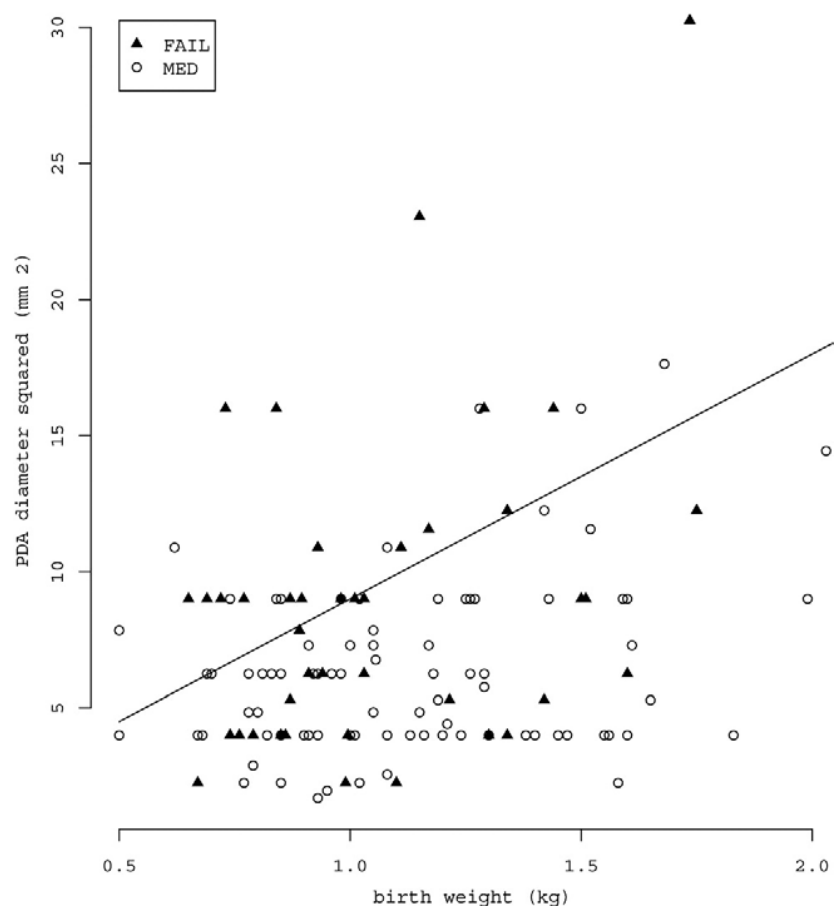

Figure 1. Scatter plot of all patients from both groups depicting the relationship between PDA diameter squared and weight at birth. PDA, Persistent ductus arteriosus.

In our sample $87.5 \%$ of patients in the MED group had a value of less than $9 \mathrm{~mm}^{2} / \mathrm{kg}$, at which medical treatment appropriately achieved PDA closure. By using this cutoff value, only $12.5 \%$ of the MED group had a value of greater than $9 \mathrm{~mm}^{2} / \mathrm{kg}$ and would have inappropriately been sent directly to surgical intervention without a prior medical trial (false-positive result). On the other hand, $41.5 \%$ of the patients in the FAIL group had an index of greater than 9 $\mathrm{mm}^{2} / \mathrm{kg}$ and could have benefited from direct surgical re- ferral, without wasting time for indomethacin failure, if this index is validated. The cutoff value at $9 \mathrm{~mm}^{2} / \mathrm{kg}$ might represent a useful value for predicting in which patients the medical treatment will succeed and which patients should probably undergo surgical intervention rapidly after an initial medical trial (Figure 1).

As described in Table 1, the preoperative left atrium/aortic root ratio was significantly smaller in the MED group (1.57 \pm $0.26)$ compared with that in the FAIL group $(1.72 \pm 0.39, P=$ .01 ). The comorbidities associated with PDA (chronic lung disease, intraventricular hemorrhage, necrotizing enterocolitis, or retinopathy) were comparable in both groups. When specifically considering the 33 surgically treated infants of the FAIL group compared with those of the MED group, there is a significant difference with regard to chronic lung disease: $16(48 \%)$ of 33 versus 44 (29\%) of 154 in the MED group $(P<.05)$. Importantly, there was a significant difference in the amount of infants receiving preoperative inotropes, with $29 \%$ in the MED group compared with $64 \%$ in the FAIL group $(P<.001)$. This illustrates the number of patients in an unstable hemodynamic condition who either make it to surgical intervention or die before surgical closure is possible (12/47 [25.5\%]; Table 1).

Comparison between the assisted respiration and hospitalization times of the 2 groups is depicted in Table 2. Assisted respiration time before PDA closure was significantly $(P<.001)$ shorter in the MED group $(9 \pm 7.2$ days $)$ than in the FAIL group ( $20 \pm 14$ days). There was no significant difference in assisted respiration time after PDA closure between the groups (MED group, $12 \pm 13.2$ days; FAIL group, $11 \pm 14.9$ days). The time spent in the intensive care unit differed significantly between the 2 groups (MED group: $21 \pm 15.1$ days vs FAIL group: $34 \pm 30.8$ days, $P=.001)$. The MED group had a significantly $(P<.01)$ shorter hospitalization time $(75 \pm 33.8$ days $)$ than the FAIL group $(100 \pm 35.1$ days $)$. When counting only the time of hospitalization after the PDA was closed, there was no signif-

TABLE 1. Characteristics of the 2 groups

\begin{tabular}{|c|c|c|c|}
\hline & $\begin{array}{l}\text { Successful medical closure, } \\
\text { MED group ( } n=154)\end{array}$ & $\begin{array}{l}\text { Failed medical closure, } \\
\text { FAIL group ( } n=47 \text { ) }\end{array}$ & $P$ value \\
\hline PDA diameter & $2.4(0.6) ; n=88$ & $2.8(0.9) ; n=41$ & $<.01$ \\
\hline Birth weight $(\mathrm{kg})$ & $1.1(0.3)$ & $1.1(0.3)$ & NS (.069) \\
\hline LA/Ao ratio & $1.57(0.26) ; \mathrm{n}=118$ & $1.72(0.39) ; n=36$ & .01 \\
\hline Inotropes & $30(64 \%)$ & $44(29 \%)$ & $<.001$ \\
\hline Chronic lung disease & $44(29 \%)$ & $16(34 \%)$ & NS \\
\hline Bradycardia-apnea syndrome & $118(77 \%)$ & $29(62 \%)$ & NS \\
\hline Intraventricular hemorrhage & $43(28 \%)$ & $17(36 \%)$ & NS \\
\hline Necrotizing enterocolitis & $13(8 \%)$ & $9(19 \%)$ & NS \\
\hline Retinopathy & $33(21 \%)$ & $10(21 \%)$ & NS \\
\hline
\end{tabular}

Means (standard deviation) are shown for continuous variables, and counts (percentage) are shown for binary variables. PDA, Patent ductus arteriosus; $N S$, not significant; $L A / A o$, left atrium/aortic root. 
TABLE 2. Respiration and hospitalization times in the 2 groups

\begin{tabular}{|c|c|c|c|}
\hline & $\begin{array}{l}\text { Successful medical closure, } \\
\text { MED group }(\mathrm{n}=141)\end{array}$ & $\begin{array}{l}\text { Failed medical closure, } \\
\text { FAIL group }(n=31)\end{array}$ & $P$ value \\
\hline Respiration time before PDA closure (d) & $9(7.2)$ & $20(14)$ & $<.001$ \\
\hline Respiration time after PDA closure (d) & $12(13.2)$ & $11(14.8)$ & NS \\
\hline Total hospitalization time (d) & $75(33.8)$ & $100(35.1)$ & $<.01$ \\
\hline Hospitalization time after PDA closure (d) & $64(33.1)$ & $69(37.3)$ & NS \\
\hline
\end{tabular}

Data are presented as means (standard deviation). PDA, Patent ductus arteriosus; NS, not significant.

icant difference between the 2 groups (MED group: $64 \pm 33.1$ days vs FAIL group: $69 \pm 37.3$ days, Table 2).

The overall mortality was $14 \%$. There was a significant difference in mortality between the 2 groups (8\% [13/154] in the MED group and 34\% [16/47] in the FAIL group, $P<$ .001). Comparing only the surgically treated infants from the FAIL group (4/33 [12\%]) with the MED group, there was no significant difference in mortality. The mortality of surgically treated neonates who underwent surgical intervention without a prior medical trial because of contraindications or hemodynamic instability was $11 \%$ (1/9). Among all surgical patients, there was 1 postoperative chylothorax and 1 recurrent nerve paresis.

\section{Discussion}

In premature neonates, a PDA is a common and potentially life-threatening condition. ${ }^{1,10-14}$ and early closure of a PDA improves cardiorespiratory status. ${ }^{9}$ Medical and technologic advances have improved the survival of preterm infants, thus extending the limits of viability. ${ }^{12}$ Common treatment of a PDA is a stepwise escalation and begins with cyclooxygenase inhibitors, although protocols in centers vary strongly with regard to patient selection and when and how to treat them. ${ }^{13}$ The indication for surgical intervention is usually given when medical treatment fails, ${ }^{15-18}$ when there are contraindications to medication, or in the face of hemodynamic instability despite inotropic support. ${ }^{7}$ In the absence of these settings, no study has demonstrated clear indications for earlier "elective" surgical referral, predicting a favorable outcome. In their series of 197 premature infants undergoing PDA ligation, Raval and colleagues ${ }^{15}$ reported greater gestational age, older age, larger size, and lesser ventilatory support at the time of surgical intervention to be associated with better outcomes, although they found no absolute cutoff values.

Early surgical closure, compared with ligation performed at a later stage, is associated with improved short-term ventilatory parameters and pulmonary function, more rapid achievement of full oral feeding, and improved body growth. ${ }^{11,14}$ In our series there was a higher tendency toward comorbidities in the FAIL group compared with the MED group. More specifically, when considering only the surgical group, the incidence of preoperative chronic lung disease was significantly more increased compared with that in the MED group. It is only speculative to think that earlier PDA closure with direct surgical referral of neonates having an index of greater than $9 \mathrm{~mm}^{2} / \mathrm{kg}$ would reduce the incidence of chronic lung disease through reduced assisted respiration times and intensive care stay. Indeed, other groups have demonstrated that delaying surgical ligation might increase the likelihood of morbidity, mortality, or both. ${ }^{17,18}$

We found relatively rapid improvements in pulmonary function after surgical PDA closure, with postclosure assisted respiration times similar to those after medical treatment, despite the longer preoperative and total assisted respiration times, higher inotrope requirements, and longer intensive care unit stays with potential iatrogenic complications in the group of patients who underwent surgical intervention. This would argue in favor of early shunt elimination, with its beneficial effect on lung function. Contrary to our findings, Raval and colleagues ${ }^{15}$ did not observe rapid improvements in cardiorespiratory status, with a significant portion of patients going on to have chronic lung disease, even after shunt elimination. Nonetheless, they do not advocate delaying surgical closure and find no contraindications to attempt PDA ligation, regardless of how small, premature, or unstable the patient's status preoperatively.

The significant difference in mortality between the 2 groups might be misleading: the FAIL group includes patients who died before they were able to be transferred to the surgical department. When taking into account only the surgically treated neonates, there is no significant difference in mortality compared with the MED group, with only 4 postoperative deaths, the last in 1991. Therefore mortality does not seem to be related to the surgical procedure itself but rather to the underlying disease and complications of prematurity.

A larger PDA has been a significant predictor of high failure of indomethacin therapy. ${ }^{16}$ Our study supports these results in that prostaglandin synthetase inhibitors failed to close the PDA with larger diameters, indexed to the respective birth weight of the patient. Based on our findings, we propose an index, dividing the squared PDA diameter (in square millimeters) by the birth weight (in kilograms, Figure 1). Assuming a cutoff value of greater than 9 $\mathrm{mm}^{2} / \mathrm{kg}$, it is possible to correctly predict $41.5 \%$ of 
medication failures that will eventually require surgical intervention, and only $12.5 \%$ of patients would inappropriately be sent directly to surgical intervention without a medication trial that might have succeeded. Although the study by Raval and colleagues ${ }^{15}$ also advocates earlier PDA ligation in unfavorable clinical settings, they found limited predictive values of PDA size or chest radiographic findings with regard to final outcome.

The limitations to this retrospective study covering 20 years are inherent in the historical changes that have occurred in neonatal care over time. Also, it is important to state that the timing of indomethacin initiation is essential to the success rate of PDA closure (ie, the sooner, the better). In our study it was not possible to retrieve this information from the charts, and better outcome rates could be expected with earlier initiation of medical treatment. This study only looked at the possibility of classical open surgery to further treat a PDA after medication, and video-assisted thoracoscopic surgery was not taken into account.

In conclusion, PDA closure is still achieved in a very high percentage of premature neonates with medical treatment when the index of PDA diameter squared/birth weight is less than $9 \mathrm{~mm}^{2} / \mathrm{kg}$. In the absence of hemodynamic instability and contraindications to medication, it remains a valid initial therapy. Patients with an index of greater than $9 \mathrm{~mm}^{2} / \mathrm{kg}$ would probably benefit from early direct surgical closure without delay at the end of any given medical protocol, thus reducing preoperative assisted respiration time and intensive care unit stay, as well as reducing costs from overall shorter hospital stay. The effect of earlier surgical intervention on oxygen dependence and chronic lung disease remains to be studied, and further research is required to validate the accuracy of this index.

We thank Dr Walter Kistler and the Neonatology team of the Children's Hospital of St Gallen, Switzerland, for the surgical assistance, referral, and perioperative care of some of the patients presented in this series.

\section{References}

1. Gersony WM, Peckham GJ, Ellison RC, Miettinen OS, Nadas AS. Effects of indomethacin in premature infants with patent ductus arteriosus: results of a national collaborative study. J Pediatr. 1983;102: 895-906.
2. Jan SL, Hwang B, Fu YC, Chi CS. Prediction of ductus arteriosus closure by neonatal screening echocardiography. Int J Cardiovasc Imaging. 2004;20:349-56

3. Van Overmeire B, Smets K, Lecoutere D, Van de Broek H, Weyler J, Degroote K, et al. A comparison of ibuprofen and indomethacin for closure of patent ductus arteriosus. N Engl J Med. 2000;343:674-81.

4. Jim WT, Chiu NC, Chen MR, Hung HY, Kao HA, Hsu CH, et al. Cerebral hemodynamic change and intraventricular hemorrhage in very low birth weight infants with patent ductus arteriosus. Ultrasound Med Biol. 2005;31:197-202.

5. Lee LCL, Tillett A, Tulloh R, Yates R, Kelsall W. Outcome following patent ductus arteriosus ligation in premature infants: a retrospective cohort analysis. BMC Pediatr. 2006;6:15-21.

6. Bancalari E. Changes in the pathogenesis and prevention of chronic lung disease of prematurity. Am J Perinatol. 2001;18:1-9.

7. Cassady G, Crouse DT, Kirklin JW, Strange MJ, Joiner CH, Godoy G, et al. A randomized, controlled trial of very early prophylactic ligation of the ductus arteriosus in babies who weighed $1000 \mathrm{~g}$ or less at birth. N Engl J Med. 1989;320:1511-6.

8. Kabra NS, Schmidt B, Roberts RS, Doyle LW, Papile L, Fanaroff A. Neurosensory impairment after surgical closure of patent ductus arteriosus in extremely low birth weight infants: results from the Trial of Indomethacin Prophylaxis in Preterms. J Pediatr. 2007;150:229-34.

9. Ghosh PK, Lubliner J, Mogilner M, Yakirevich V, Vidne BA. Patent ductus arteriosus in premature infants. Tex Heart Inst J. 1986;13: 163-8.

10. Shenassa H, Sankaran K, Duncan W, Tyrrell M, Bharadwaj B. Surgical ligation of patent ductus arteriosus in a neonatal intensive care setting is safe and cost effective. Can J Cardiol. 1986;2:353-5.

11. Jaillard S, Larrue B, Rakza T, Magnenant E, Warembourg H, Storme L. Consequences of delayed surgical closure of patent ductus arteriosus in very premature infants. Ann Thorac Surg. 2006;81:231-4.

12. Sanders MR, Donohue PK, Oberdorf MA, Rosenkrantz TS, Allen MC Perceptions of the limit of viability: neonatologists' attitudes toward extremely preterm infants. J Perinatol. 1995;15:494-502.

13. Laughon M, Bose C, Clark R. Treatment strategies to prevent or close a patent ductus arteriosus in preterm infants and outcomes. J Perinatol. 2007;27:164-70.

14. Szymankiewicz M, Hodgman JE, Siassi B, Gadzinowski J. Mechanics of breathing after surgical ligation of patent ductus arteriosus in newborns with respiratory distress syndrome. Biol Neonate. 2004;85: 32-6.

15. Raval MV, Laughon MM, Bose CL, Phillips JD. Patent ductus arteriosus ligation in premature infants: who really benefits, and at what cost? J Pediatr Surg. 2007;42:69-75.

16. Boo NY, Bilkis MA, Bilkis AA, Yong-Junina F. Predictors of failed closure of patent ductus arteriosus with indomethacin. Singapore Med J. 2006;47:763-8.

17. Little DC, Pratt TC, Blalock SE, Krauss DR, Cooney DR, Custer MD. Patent ductus arteriosus in micropreemies and full-term infants: the relative merits of surgical ligation versus indomethacin treatment. J Pediatr Surg. 2003;38:492-6.

18. Truog WE, Jackson C, Badura RJ, Sorensen GK, Murphy JH, Woodrum DE. Bronchopulmonary dysplasia and pulmonary insufficiency of prematurity. Lack of correlation of outcome with gas exchange abnormalities at 1 month of age. Am J Dis Child. 1985;139:351-4. 